\title{
The Ways of Cultivating College Students' Independent Entrepreneurship
}

\author{
Xilan Wu \\ Jiangxi Science and Technology Normal University, Nanchang Jiangxi, 330013, China
}

Keywords: University students, Entrepreneurial skills, Cultivating.

\begin{abstract}
With the continuous improvement of our socialist economic system and the gradual improvement of people's living standard, the government and the education department pay great attention to education, and the number of college students is increasing. At present, the employment of college students has been a hot topic, However, the educational ability and practical ability of college students' own entrepreneurship are very lacking. The college students are lack of cognition of entrepreneurship. This is to study the ability of independent students to improve their own ability. The University 's Cognition of University Education and the Improvement of the Starting Ability of College Students in China.
\end{abstract}

\section{Introduction}

In the face of fierce competition in the job market, entrepreneurship has gradually become the choice of college students, college students entrepreneurship is also an important part of our social market, on the one hand for college students more employment of a way, on the other hand can drive China's economic development, many students to provide employment platform to promote social development and progress of one of the important conditions, but also to achieve self-improvement of college students, so the report clearly stated in the 17th, to implement the expansion of employment development strategy to promote entrepreneurship to promote employment more workers become employed, which makes the majority of the unemployed into the community pointed out a very good employment direction, but today's college students are more knowledge from the textbooks, lack of entrepreneurial awareness and entrepreneurial skills, the lack of market The lack of career planning, knowledge in the school can not cope with the market demand, entrepreneurial business philosophy and entrepreneurial ability can not adapt to the fierce competition in the market, so for the country to provide good opportunities and missed, even if the final choice start a business because of their lack of ability, experience foot, eventually eliminated society, can not understand the market, today's college students lack self-awareness, lack of understanding of the market and the rationality of the market judgments, the majority of students for the market is no stranger to the word, but the market is what, what purposes but no knowledge, but blind to the venture As the trend of entrepreneurship, the government to the market as a macro-control, but the majority of students for micro-control and macro-control little understanding, and whim to start, do not know how to follow the rules of the market and the scientific awareness of the market blindly entrepreneurial, trend, students start with a general family support mainly loans, but a great venture, failed unable to sustain long-term, it is impossible to formulate long-term development strategy and program objectives.

\section{The Ways of University Students' Ability of Independent Entrepreneurship}

\section{Organization and management ability}

Organizational management is a team of souls, with a more organized mind to gather more ideas, he is more able to achieve a great role in achieving the goal, the flexibility to organize the various forces to rationalize the integration and coordination of all aspects of management And the staff, a key role for a team, for a good team must have a good organization and management personnel, the ability for 
a team has a certain influence, can make the team's internal and external resources effectively combined, today's college students Mostly only children, more only consider themselves, and not too long people get along, so we should be more training organization and management personnel to ensure that the entire team can be an orderly long-term operation.

\section{Practice and experience}

Today's college students have a strong theoretical knowledge of books, but also the so-called dead reading, paper, today's college students' ability to operate and its weak, entrepreneurial direction is very confused, limited scope of activities, but students are often living in the campus, Good contact, but also can not access the actual management level of the lack of management capacity and the lack of practical management experience, so college students should be more involved in practical activities, but they lack from a student age to the professional era of change, Entrepreneurial identity change, a good foundation is the beginning of all success, so college students should follow the trend of the times, the University should be prepared for the future of the venture, this will accumulate more experience, just enter the stage we should Actively into the school community, and then understand their own interests, to develop their own personality for the future to do a better foundation for entrepreneurship, which will make self-worth to improve, but also to their own practical ability to further develop into the junior, the school should Provide social practice, let Students through social practice activities to understand the market and society, so that students in advance to experience the depth of society, but also for entrepreneurship with some initial awareness, a lot of practice, to learn more, to grasp the prospects for social development in the community needs to reflect Self-worth, self-affirmation, for the future to provide more self-confidence, social practice can provide opportunities for mistakes in the future, more entrepreneurial self-reflection and adjustment to provide a reference. In practice can accurately positioning for their own, to see their own heart quality, good quality in the school during the school to exercise their own, you can know yourself earlier, during practice, to face failure, sum up experience for future entrepreneurship Better experience, the process of work to do a good job on the market awareness and market survey analysis, better grasp the market information for future business to provide better resources.

\section{Method ability}

Method ability is the salary carrier to collect, process, use the ability to include a lot of ability, today's college students are more enjoyment of life, they lack a lot of awareness of life, the ability to include a lot, 1: observation, observation Can help students find the ability to opportunity, when the opportunity to come away to grasp rather than not see, observation can find a lot of interesting things, you can also develop the market demand. 2: the implementation of capacity, in order to achieve the goal for the early and late business experience in the activities, work efficiency has been improved, spend the least time to do the most favorable things, better and most effective implementation of dynamic monitoring and regulation, Force, a team is not only a good staff is the most critical is the leadership, the leadership can lead a collective development can lead a team to a better prospect sprint, only a good leader, the following staff have Better power to develop, more positive to pay for a company, the struggle, leadership is only a team of the backbone, have a good leadership ability to better use the team goals to establish the establishment of community norms and good values, So that a team to form the internal strength and the combination of external forces perfect, the formation of group unity and cooperation ability, 3 thinking, today's college students do not like to use the brain, long-term passive form, from high school for the university and struggle to the university I do not know why the struggle to lose serious Balance, and because of the development of socialism, people living water Of the increase in the information age, so the mobile phone computer, everyone has, college students encounter more do not understand things do not like thinking but in the search on the Internet, so college students should think more, The community encounter problems learn to solve, will be better grasp the opportunity to create opportunities for the opportunity. 


\section{Learning should create a business environment, build entrepreneurial road}

The promotion of entrepreneurial capacity to enhance the need for long-term training and accumulation, learning should create a good business environment, is to cultivate the premise of self-entrepreneurial ability of students in the school small internal environment is very important to his indirect performance of a school level, But also divided into hard and soft environment, the hard environment in the school to provide students with the majority of students to provide places and infrastructure and test sites, have a good business environment Most people will go to their own curiosity and self-confidence to meet the desire to attract more The majority of students to entrepreneurship and experiment to try, so the school should strengthen the emphasis on the construction of the hard environment, the establishment of college students incubator center base, the introduction of entrepreneurial simulation of combat equipment and provide venture capital for the majority of college students to provide quality treatment, attracting students to entrepreneurial ability The school should also provide college students in the school during the independent business simulation show, often held college students "entrepreneurial forum" "works exhibition" "entrepreneurial experience exchange" schools should also be concerned about the recent exhibitions of the school to meet the students to be sure Desire, more To stimulate college students passion and interest in entrepreneurship, so that more students during the school to meet the understanding of entrepreneurship, so that more students into the entrepreneurial path, promote more economic development, to provide our country with the ability to get the level of science and technology Enhance, so just go out to practice the students to experience the hardships of society, earlier understand what is the juvenile strong country strong.

\section{Building a business bridge, build a business to accelerate the road}

Our education should be to foster entrepreneurial talents as the goal, to build the future CEO of private enterprises as the goal, we want to allow more students to achieve this goal, to let students know what is the market, so as to create more market to make students to understand, in this part of us should go to build a "simulated market" students of entrepreneurship, to enable students to advance to a new market to further understand, develop sustainable development of students, to make more in this culture More than one student interpretation of different roles to better grasp the changes in the role of each role, each role on behalf of a position, you can speculate every role of supply needs, the real role for their behalf for greater benefits, the sense of professionalism, to provide a good way for the future of the venture, which is better know the future status should better protect their own interests, on the one hand, to play different roles and imitate the real business competition, can provide their own communication skills, communication skills, and the ability to argue, to provide a good business venture in the way in the future, so that students Enough to adapt to their posts in which the ability, students become better business managers.

\section{Improve the service system, lay the escort}

Service system has become the majority of students choose to become one of the important choice of schools, so the school should provide open business network platform and service hotline, encourage more students to participate in the network interaction, so that students easy to understand the entrepreneurial activities , And to start the entrepreneurial students to set up entrepreneurial players, so that more students into, and for the players to provide a good teacher and resources, and then lead students to participate in field training, and strengthen the business credit services, entrepreneurship related knowledge , To provide legal issues, to increase students' understanding of the law, had a strong sense of legal protection, so that later entrepreneurial detours, to extract the correct values for college students to build entrepreneurial services, the establishment of archives, the establishment of a set of their own Complete entrepreneurial service system for college students, for the future to provide excellent protection of entrepreneurship, lay the road to escort the role of entrepreneurship. 


\section{Cultivate strain, protect yourself}

In today's era of rigid character is no longer demand, a person's success or not a lot of factors is the reason for self-ability, a business people, mainly by time to train out, not only includes skills and experience, more is that we do things Attitude, we should have the ability to adapt themselves, entrepreneurs in order to be able to survive in today's competitive society, it should break through their own limitations, challenge the success of the previous model and strategic means, one can challenge themselves at any time, constantly The negative self and the future can be a successful person who has a lot of contact, because a lot of things did not imagine so easy, this is even more difficult to start this business, it is step by step in the ordinary to achieve, business pre-do a lot of information to study, to study the issues raised by the venture, to make a reasonable judgment, to achieve what kind of effect, when to achieve the desired results are taken into account, each study may become The problems faced, so today's college students to read more books, constantly understand the market, Constantly thinking about the solution, and then go to the market to view, what the market now face problems, which can solve their own aspects, so that in the future business can be a good solution to many problems, to solve the problem to a solution, better More to achieve the effect of the strain, for the future business more to avoid the problems encountered in the business, better to solve the problem, follow the trend of the times, in addition, the management process should be business ideas, financing, make a credible Projections, in the success of the road after the success of the higher and higher, adapt to a variety of communication skills, guarding the business base and the results, in the future to protect themselves.

\section{References}

[1] An Analysis of the Influencing Factors of College Students' Entrepreneurial Tendency, Zhejiang University, 2006.

[2] Yang Xiaohui, The Bottleneck Problem and Strategy Choice of College Students' Entrepreneurship, China Higher Education, 2010,(18).

[3] Group Entrepreneurship Research Group, Research Report on College Students' Entrepreneurship, Journal of Guangdong Youth College of Cadre, 2006,(2). 